\title{
Brain and Law: An EEG Study of How We Decide or Not to Implement a Law
}

\author{
Armando Freitas da Rocha1, Eduardo Massad ${ }^{2,3}{ }^{*}$, Fabio Theoto Rocha1,4,5, \\ Marcelo Nascimento Burattini ${ }^{2,6}$ \\ ${ }^{1}$ Research on Natural and Artificial Intelligence (RANI), Jundiaí, Brazil \\ ${ }^{2}$ School of Medicine, University of São Paulo Brazil, São Paulo, Brazil \\ ${ }^{3}$ London School of Hygiene and Tropical Medicine, London, UK \\ ${ }^{4}$ Instituto de Pesquisas em Teoria da Informação (IPTI), Aracajú, Brazil \\ ${ }^{5}$ Laboratory of Signal Processing, Department od Electrical Engeneering, Faculdade de Engenharia Industrial, \\ São Paulo, Brazil \\ ${ }^{6}$ Escola Paulista de Medicina, Universidade Federal de São Paulo, São Paulo, Brazil \\ Email: ${ }^{*}$ edmassad@usp.br
}

Received 6 October 2014; revised 23 November 2014; accepted 7 December 2014

Copyright (C) 2014 by authors and Scientific Research Publishing Inc.

This work is licensed under the Creative Commons Attribution International License (CC BY).

http://creativecommons.org/licenses/by/4.0/

c) (i) Open Access

\section{Abstract}

Brazil has introduced a referendum regarding the prohibition of firearm commerce and propaganda arguments have invoked socially and personally driven issues in the promotion of voting in favor of and against firearm control, respectively. Here, we used different techniques to study the brain activity associated with a voter's perception of the truthfulness of these arguments and their influence on voting decisions. Low-resolution tomography was used to identify the possible different sets of neurons activated in the analysis of the different types of propaganda. Linear correlation was used to calculate the amount information $H\left(e_{i}\right)$ provided to different electrodes about how these sets of neurons enroll themselves to carry out this cognitive analysis. The results clearly showed that vote decision was not influenced by arguments that were introduced by propaganda, which was typically driven by specific social or self-interest motives. However, different neural circuits were identified in the analysis of each type of propaganda argument, independently of the declared vote (for or against the control) intention.

\section{Keywords}

EEG, Brain Mapping, Neuromarketing, Language Understanding, Politics, Election, Decision Making

\footnotetext{
${ }^{*}$ Corresponding author.
} 


\section{Introduction}

As discussed before [1]: Any living being uses all possible resources to keep maintaining its identity in space and time. This means that any living being has as primordial goals to obtain not only the resources to synthesize their constituent chemicals, to obtain energy to support the chemical transactions and to allow it to creating other similar living beings, but also to achieve some goals dependent on some more abstract matters. Because of this, living beings have sets of goals (values) to attain and as resources on Earth are finite, this creates needs for goods and services to support FSV. Needs in turn motivates the individual to act in order to satisfy them.

Man is a social being and living together generates conflicts of interests triggered by opposing personal and social needs. Morality and law are aimed to offer solutions to solve or avoid these conflicts, providing two distinct sets of rules or norms for such a purpose. Whenever rules are broken and wrongdoing is established, punishment has to be provided and enforced to avoid future norm breaking. Wrong doing is prevented by coercion. Moral enforcement is a matter for divine or community reproach; therefore the degree of coercion of moral rules is low. In case of law, enforcement is the matter of Justice and Government. Justice is in charge of judging wrong doing and prescribing punishment, while Government is in charge of enforcing punishment [2] [3].

Positive law is a man-made law that obliges or specifies an action establishing specific rights for an individual or group in order to prevent wrong doing that may cause damage for the individual or group [4] [5]. To create a positive law is, therefore, necessary to identify a damage avoided and define an action to prevent it. A good positive law is well justified by an important threat to the individual and/or group and proposes effective action to prevent this well identified menace (e.g. [4]).

From time to time, tragedies like Newtown, CN shooting trigger waves of heated and emotional debates about some sort of gun control are basically polarized at two opposite ends of a broad spectrum: personal liberties versus safety and firearm injury. Proposals for gun control laws vary widely from country to country; while some countries try to restrict the sales of highly destructive weapons, other countries try to restrict the sales of all types of weapons. Within this second group, Brazil has recently carried out a referendum regarding the prohibition of firearm commerce (FC).

Media propaganda (Table 1) used arguments (PA) tried, either to convince voters about the treat to the individual and society of having a free firearm commerce (YA) in order to promote voting in favor (Yes) firearm commerce control, or to stress the inefficacy of this kind of control (NA) in order to promote voting against (No) it (see Table 1). If PA was believed and NA discredited, firearm commerce control would be considered as an efficient way to prevent the damage caused by firearm house accident, traffic dispute, mass killing, etc. On the contrary if NA was not believed or PA discredited, firearm control should be ruled out in the referendum. However, to this true, voters would have to consider that propaganda influenced their voting.

YA and NA have different ontological origins. YAs are based on empirical facts because any threat is about incurred damage (see Table 1). Because of this, YA analysis requires recalling information from episodic memory. In contrast, NAs are supported by reasoning about personal versus collective rights, causes of criminality, etc. (see Table 1). Because of this, NA analysis requires using neural circuits supporting analytical reasoning.

The possible influence of a propaganda argument on vote decision depends on the supposed social threat being considered as real and important in YA case, or the alleged proposition being considered as right and implying and important personal loss in NA case. The threat veracity (Table 1 ) demands its probability $(p)$ being higher than zero, whereas its importance directly depends on $p$ and the possible damage. Logical inference determines proposition veracity (Table 1 ) and the probability of failing to implement an adequate firearm control as well as the expected personal damage due to this failure is suggested to be high if the proposition is considered to be true. In this line of reasoning, highly probable believed YA would justify voting for firearm commerce control, while highly accepted NA would justify voting against the control. In order to influence vote decision, any PA has to justify one type of voting, but as each voter may have their own reasons (R) for voting Yes or No, even a justified PA may be of no influence if it does not match one of these reasons or it is not motivated by media propaganda to be included in $\mathrm{R}$.

Rocha et al. [6] employed Principal Component Analysis (PCA) to study the amount of information $H\left(e_{i}\right)$ provided by electrode $e_{i}$ about vote intention one week prior to Election Day and showed that brain activity differed for "Yes" and "No" voters. "Yes" voters recruited neural circuits that have been previously described [7] in the Theory of Mind (ToM), which are involved in mentalizing third party intentions and important in the analyses of social issues. In contrast, "No" voters recruited neural circuits that have been shown to be involved 
Table 1. Poll opinion questionnaire.

Select a response below that best describes your opinion about the ban on firearm commerce in Brazil.

You may provide a second response if you believe that your first response may change by Election Day:
1) I will certainly vote No,
1) I will certainly vote No,
2) I will probably vote No,
2) I will probably vote No,
3) Certainly, I will not vote No,
3) Certainly, I will not vote No,
4) I have not yet decided my vote,
4) I have not yet decided my vote,
5) I will certainly vote Yes,
5) I will certainly vote Yes,
6) I will probably vote Yes,
6) I will probably vote Yes,
7) Certainly, I will not vote Yes.
7) Certainly, I will not vote Yes.

First opinion

Second opinion

Here, you are asked to provide your opinion about some statements that have been made in free propaganda on the radio and TV. Please select one of the following options that best describes your opinion about this statement:
a) I believe
b) I do not believe
c) I have no opinion

Please select one of the following options to evaluate the if this statement justify voting in the referendum:
a) It justifies
b) It does justify
c) I do not know

Please select one of the following options to evaluate the influence of this statement on your vote on Election Day:

$\begin{array}{lll}\text { a) It will influence my vote } & \text { b) It will not influence my vote } & \text { c) I do not know }\end{array}$

1 or Y1: A gun in the house may cause a fatal accident, killing innocent people, mainly children. You may prevent such events by banning firearm commerce.

2 or N1: People have the right to defend themselves from criminals. The proposal of banning firearm commerce hurts your personal rights.

3 or Y2: Having a gun facilitates murder in the case of a neighboring, family or traffic dispute. You may prevent such events by banning firearm commerce.

4 or Y3: The robbery of firearms from an honest citizen is the main source of guns for criminals. You may contribute to disarm criminals by banning firearm commerce.

5 or N2: To ban firearm commerce disarms honest citizens but not criminals.

6 or N3: To prohibit firearm commerce will not reduce criminal rates.

with self-awareness and self-related processing [7]-[10].

In this context and from the above discussion, the following questions arise:

1) Are different neural circuits involved in YA and NA analysis because each type of argumentation has different ontological origins?

2) Is YA analysis mostly supported by episodic memory and social centered neural circuits and NA analysis mostly supported by analytical and self-related processing neural circuits?

In their study, Rocha et al. [6] asked 1136 people to complete a poll opinion questionnaire (PQ) to evaluate how true media propaganda arguments (PA) were, how much PA justified the referendum and how much the PA would influence their vote. In addition, 32 randomly selected individuals had their EEG recorded during their PQ responses. Here we used Loreta technology [11] and PCA analysis [6] to study 3 different EEG epochs of 2 seconds prior to the moments when the truth $(\mathrm{T})$, justification $(\mathrm{J})$ and influence $(\mathrm{J})$ evaluations were decided, in order to test the hypotheses raised by questions 1 and 2 above.

\section{Materials and Methods}

\subsection{Poll Opinion}

A total of 1136 people living in the Great São Paulo area, a region inhabited by approximately 16 million people during the week that preceded the National Fire Arm Referendum, answered a poll opinion questionnaire (Table 1) about voting intention and propaganda arguments in favor $(\mathrm{Y})$ and against $(\mathrm{N})$ firearm commerce prohibition. Table 2 provides information on the sample population. 
Table 2. Characteristics of the sample population.

\begin{tabular}{crccccccc}
\hline & Age & \multicolumn{2}{c}{ Gender } & \multicolumn{2}{c}{ Instruction } & \multicolumn{2}{c}{ Income } \\
\hline Mean & 35 & Female & 0.42 & Primary School & 0.17 & Low & 0.41 \\
Max & 63 & Male & 0.58 & High School & 0.30 & Medium & 0.44 \\
Min & 18 & & & College & 0.53 & High & 0.27 \\
\hline
\end{tabular}

The questionnaire shown in Table 2 was aimed to provide information about:

1) the intended vote (v) on the Brazilian Firearm Referendum;

2) a second voting opinion (v') if the volunteers would change his/her opinion before the Election Day;

3 ) the truth of the propaganda arguments in favor of $(\mathrm{Y})$ and against $(\mathrm{N})$ firearm commerce prohibition;

4) if each argument justified $(\mathrm{Y})$ or $(\mathrm{N})$ the referendum; and

5 ) if each argument would influence $(\mathrm{Y})$ or $(\mathrm{N})$ the individual's voting intention.

Note that, as we intended to study the correlation between arguments and voting intention, and not voting decision-making, we carried out the measurements one week before the moment of voting.

PCA analysis confirmed the distinction between $\mathrm{Y}$ and $\mathrm{N}$ arguments because responses to the poll questions were divided into distinct components, as shown in Table 3.

\subsection{EEG Recordings}

Sixteen females and 16 males (Table 2), all Caucasians and aged from 20 to 57 years old, were selected to have their EEG recorded (electrodes were placed according to the 10/20 system with an impedance of less than 10 kohm; low bandpass filter (50 Hz); a sampling rate of $256 \mathrm{~Hz}$ and 10 bit resolution, and ear lobe reference) while responding to the PQ. The EEG was visually inspected for artifacts prior to its processing, and the events associated with a poor EEG (e.g., when eye movements could compromise the results of the regression analysis) were discarded.

Two networked personal computers were used in the present study: one for the EEG recording and the other to sequentially display the different arguments in Table 1, where the individual's evaluation of each argument's truth (Yes or No) was requested. If it did (Yes) or did not (No) justify the referendum and if it would (Yes) or would not (No) influence the individual's vote intention. The volunteers were allowed to take as much time as they needed to make their decisions as well as to indicate whether they were undecided about any of these questions. We recorded the following times, $t_{o}^{T}$ and $t_{d}^{T}$, as the time question when the argument truth was introduced and the time of individual's decision, respectively; $t_{o}^{J}$ and $t_{d}^{J}$ represented the time question about the referendum justification was introduced and the time of the individual's decision, respectively, and $t_{o}^{I}$ and $t_{d}^{I}$ represented the time question about the argument voting influence was introduced and the time of the individual's decision, respectively. The following EEG epochs were obtained for the analysis: $t_{d}^{T}-\Delta ; t_{d}^{J}-\Delta$ and $t_{d}^{I}-\Delta$. The value of $\Delta$ was set as 2 seconds to ensure the volunteers were allowed sufficient time to reason and to make a decision that did not compromise our analysis.

Low Resolution Electromagnetic Tomography (Loreta), which was developed by Pascual-Marqui [11], was used to localize the potential EEG source generators $s_{l}$. The corresponding T, J and I EEG epochs were averaged for each electrode into different files according to each argument type ( $\mathrm{Y}$ or $\mathrm{N}$ ), which generated the EEG averaged files $\mathrm{T}_{\mathrm{Y}}$ and $\mathrm{T}_{\mathrm{N}} ; \mathrm{J}_{\mathrm{Y}}$ and $\mathrm{J}_{\mathrm{N}}$; and $\mathrm{I}_{\mathrm{Y}}$ and $\mathrm{I}_{\mathrm{N}}$; respectively. Each of these files consisted of the corresponding EEG averages that were calculated for each of the 20 electrodes used to record the associated electrical activity for each decision epoch. A grand average was calculated for each of these files, and the corresponding z-score determined the EEG times that were statistically significant for the Loreta Analysis. Only those EEG moments with a z-score greater than 1.961 (5\% significance level) were selected for this analysis (Figure 1). Only the areas showing the best match for each selected EEG moment was assumed as potential EEG source generators $s_{l}$. Loreta analyses provided anatomical information and the Brodmann area number to localize the source of the EEG activity that was recorded at each selected time.

The amount of information $H\left(e_{i}\right)$ provided by electrode $e_{i}$ was calculated to summarize information by electrodes $e_{i}$ about the identified sources $s_{l}$. Because EEG data are assumed to be a weighted sum of the electrical activity of different sources, correlation analysis of the EEG activity $d_{i}(t)$ recorded by the different electrodes $e_{i}$ may be used to calculate $H\left(e_{i}\right)$ in order to summarize information provided by each electrode 
Table 3. PCA analysis of poll opinion the questionnaire responses.

\begin{tabular}{|c|c|c|c|c|c|c|}
\hline & \multicolumn{2}{|c|}{$\mathrm{T}$} & \multicolumn{2}{|c|}{$\mathrm{J}$} & \multicolumn{2}{|c|}{ I } \\
\hline & $\mathrm{F} 1$ & F2 & F1 & F2 & F1 & F2 \\
\hline Y1 & 0.83 & 0.02 & 0.86 & 0.19 & 0.88 & 0.03 \\
\hline N1 & -0.09 & 0.74 & 0.081 & 0.78 & 0.13 & 0.77 \\
\hline Y2 & 0.77 & -0.03 & 0.85 & 0.10 & 0.85 & 0.08 \\
\hline Y3 & 0.40 & -0.05 & 0.79 & 0.27 & 0.81 & 0.18 \\
\hline N2 & 0.27 & 0.69 & 0.22 & 0.76 & 0.12 & 0.80 \\
\hline N3 & -0.17 & 0.66 & 0.42 & 0.65 & -0.1 & 0.62 \\
\hline $\mathrm{EV}$ & 2.22 & 1.58 & 1.58 & 1.49 & 2.22 & 1.58 \\
\hline $\mathrm{P}$ & 0.37 & 0.26 & 0.26 & 0.24 & 0.37 & 0.26 \\
\hline
\end{tabular}

$$
\text { Yes }
$$

No
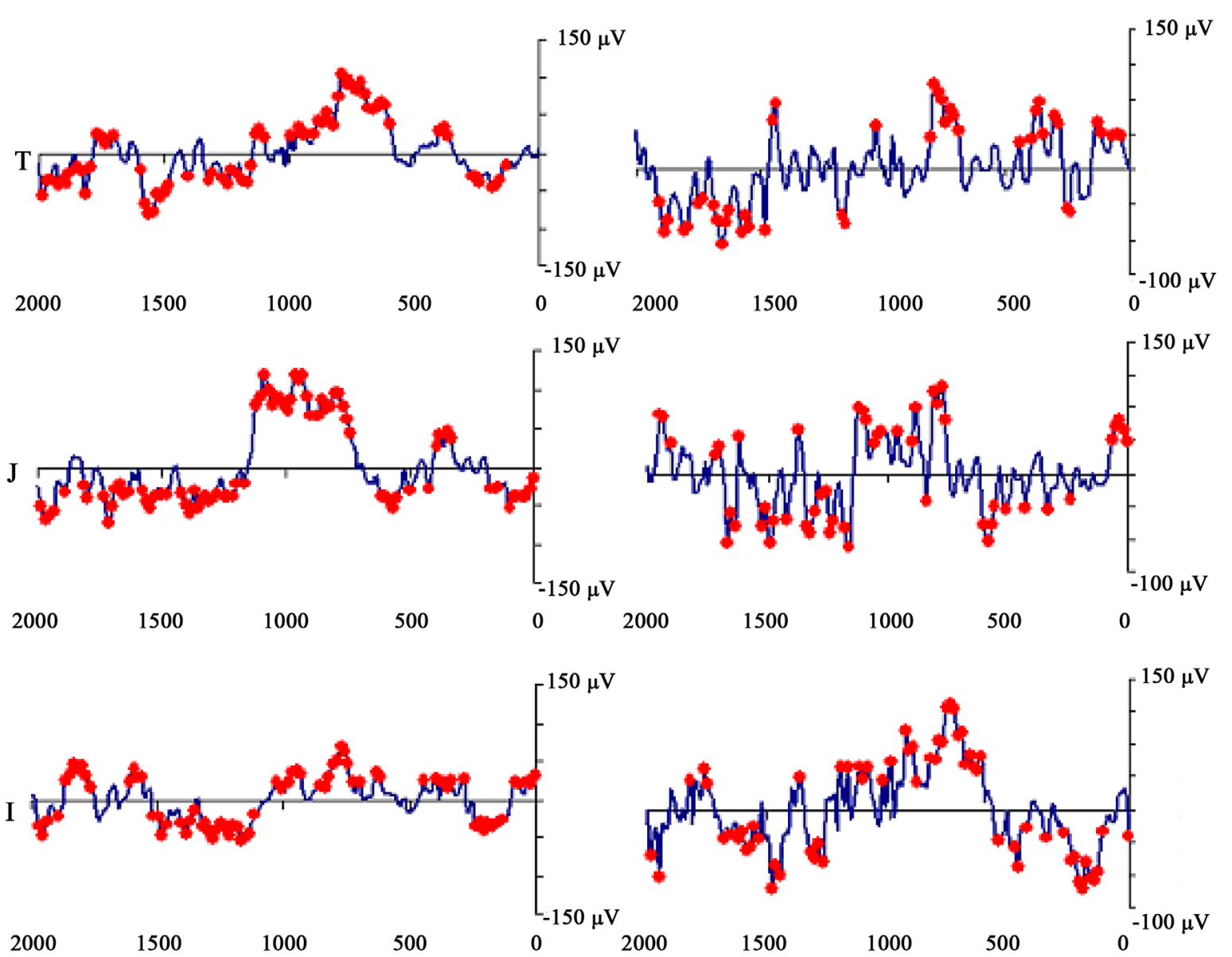

Figure 1. Grand average calculated for $T_{Y}, J_{Y}$ and $I_{Y}$ (left), $J_{Y}$ and $T_{N}$ and $I_{N}$ (right). The red dots mark the EEG moments that were used for the Loreta calculations because their $\mathrm{Z}$-scores were above 1.961 .

$e_{i}$ about all involved sources $s_{i}$ into a single variable as proposed by Rocha et al. [6] [12]. The rationality is the following.

The Pearson correlation $\mathrm{R}$ is +1 in the case of a perfect positive (increasing) linear relationship (correlation), 
-1 in the case of a perfect decreasing (negative) linear relationship (anticorrelation), and some value between -1 and +1 in all other cases, indicating the degree of linear dependence between the variables. As it approaches zero there is less of a relationship (closer to uncorrelated). The closer the coefficient is to either -1 or +1 , the stronger the correlation between the variables. In this context, the correlation strength $r$ is equal to $|R|$. If data $d_{i}(t), d_{j}(t)$ furnished by two electrodes $e_{i}, e_{j}$ provide equivalent information about sources $s_{i}$ then Pearson correlation coefficient $R_{i, j}$ calculated for $d_{i}(t), d_{j}(t)$ will approach \pm 1 , otherwise it will approach 0 . The highest uncertainty about the information equivalence provided by $e_{i}, e_{j}$ occurs when the correlation strength $r_{i, j}$ approaches 0.5 . Therefore, in the same line of reasoning used by Shannon to define the amount of information provided by a random variable, it is proposed that the informational equivalence, $H\left(r_{i, j}\right)$ of $d_{i}(t), d_{j}(t)$ furnished by $e_{i}, e_{j}$ is the expected value $E\left(I\left(r_{i, j}\right)\right)$ of the information $I\left(r_{i, j}\right)$, provided by $r_{i, j}$. Therefore:

$$
H\left(r_{i, j}\right)=E\left(r_{i, j}\right)=-\left\{r_{i, j} \log _{2}\left(r_{i, j}\right)+\left(1-r_{i, j}\right) \log _{2}\left(1-r_{i, j}\right)\right\}
$$

Such that if $r_{i, j}=0.5$ then $H\left(r_{i, j}\right)=1$ and if $r_{i, j}=1$ or $r_{i, j}=0$ then $H\left(r_{i, j}\right)=0$.

Now, given

$$
r_{i}=\frac{\sum_{j=1}^{19} r_{i, j}}{19}
$$

the entropy of $\overline{r_{i}}$ is

$$
H\left(\bar{r}_{i}\right)=-K\left\{r_{i, j} \log _{2}\left(\bar{r}_{i, j}\right)+\left(1-\bar{r}_{i, j}\right) \log _{2}\left(1-\bar{r}_{i, j}\right)\right\}
$$

and it quantifies the mean informational equivalence from $d_{i}(t)$ concerning that provided by all other $d_{j}(t)$, because the different electrodes (information channels) provide different, but correlated, information about $s_{i}$.

In this context, we propose that

$$
H\left(e_{i}\right)=\frac{\sum_{j=1}^{19}\left[h\left(\bar{r}_{i}\right)-h\left(r_{i, j}\right)\right]}{19}
$$

quantifies the information provided by $d_{i}(t)$ about the sources $s_{i}$ involved in a cognitive task solving, because

a) if $r_{i, j}=k$ for all $e_{j}$ then $\bar{r}_{i}=k, H\left(r_{i, j}\right)=H\left(\bar{r}_{i}\right)$ for all $e_{j}$, and consequently $H\left(e_{i}\right)=0$. This indicates that $d_{i}(t) e_{i}$ does not provide any additional information about the sources $s_{i}$;

b) for all other conditions $0<H\left(e_{i}\right)<1$ and quantifies the information provided by $d_{i}(t)$ about the sources $s_{i}$.

Principal Component Analysis (PCA) is a statistical tool to investigate patterns of covariation in a large number of variables and to determine if information may be condensed into small sets of these variables called principal components [12]. This transformation is defined in such a way that the first principal component is the one that accounts for as much of the variability in the data as possible, and each succeeding component in turn explain the subsequent amount of variance possible under the constraint that it be orthogonal to (i.e., uncorrelated with) the preceding components. Factorial mappings are proposed to represent the activity of the neural circuits enrolled in a cognitive task because they condensed the information provided by the electrodes sampling this neural activity. In this ways, factorial analysis does not map brain areas activated by a cognitive task, but provides information to disclose the activity of circuits composed by neurons distributed on different areas of the brain recruited by the cognitive task, because $H\left(e_{i}\right)$ measures the amount of information provided by $e_{i}$ about spatial and temporal distribution of $s_{l}$. PCA was applied here to study the covariation of $H\left(e_{i}\right)$ during each of the selected epochs. This analysis revealed that three factors had accounted for more than $80 \%$ of the covariation in $H\left(e_{i}\right)$ and that the factors had eigenvalues that were greater than 1.4. The factorial brain maps were constructed to describe the results of the PCA using the procedures employed by Rocha et al. [1] [12] taking the loading values $f_{j}\left(e_{i}\right)$ of $H\left(e_{i}\right)$ for each of the factors $F_{j}(j=1,2,3,4)$ into account. To estimate the potential similarities between each factorial brain mapping that was associated to each $F_{j}(j=1,2,3,4)$ for 
each EEG time epoch, the authors used Pearson correlation coefficients, which were calculated for their respective loading values $f_{j}\left(e_{i}\right)$.

\section{Results}

Poll opinion and EEG data analysis are described below.

\subsection{Poll Opinion}

The results obtained from the PQ analysis are shown in Table 4. All of the voters considered half of the "Yes" arguments (YA) and 76\% of the "No" arguments (NA) as true. The PA was assumed to not justify the FC by more than $75 \%$ of the individuals, and more than $64 \%$ of responders declared that this would not influence their vote. The data did not significantly change if the Yes and No voters were considered separately. These results showed that people were more convinced of the NA and coherently assumed that the PA did not justify the FC. The majority of voters declared that their voting decision would be determined by other reasons than those proposed by the PA.

\subsection{EEG Results}

PCA and Loreta analyses for each EEG epoch and the comparison of the results obtained with each technique are discusses bellow.

\subsubsection{Truth Evaluation}

Grand averages (Figure 1) were clearly different for YA and NA, having 40 significant moments (Z score greater than 1.961) in NA case and 70 of these moments in YA case. These differences resulted in two distinct LS sets of identified Loreta sources associated with Truth evaluation of each type of argument (Figure 2). Because of this PCA mappings associated with Truth evaluation were clearly different for YA and NA (Figure 2).

Loreta sources were mostly identified at BA 10, 11, 17, 18, 29 and 47 for both types of argument but the frequency these sources were located at these locations differed for NA compared to YA.

PCA disclosed the existence of 3 patterns of $H\left(e_{i}\right)$ covariation that explained more than $60 \%$ of data covariance. P1 pattern consisted of F7, T3 and P4 in the YA case and PZ and F3 in the NA case. P2 pattern mostly consisted of the responses obtained by the right frontal electrodes in the YA case and the left frontal electrodes in the NA case. P3pattern consisted of F3, C3, P3, O1, FZ, CZ, PZ, OZ, C4 and O2 in the YA case and the FZ, C3, C4, P4, PZ, OZ and O2 electrodes in the NA case.

Pearson's determination coefficient is used to calculate $H\left(e_{i}\right)$. This means that $H\left(e_{i}\right)$ measures the information provided by each $e_{i}$ about the sets of neurons activated by the cognitive task being processed. Loreta analysis identifies these sets of activated neurons and PCA discloses those electrodes providing similar information about them. Since the electrical activity recorded by each $e_{i}$ depends on the distance from the electrode to the activated neural sources $s_{l}$, the nearest $s_{l}$ to each electrode that significantly loaded in each PCA pattern are the most probable set of neurons contributing to distinguish these patterns. Figure 3 display the XY coordinates of nearest $s_{l}$ to each PCA pattern in the case of Truth evaluation and Table 5 identify these sources.

Table 4. Percentage of the different responses to the poll questions.

\begin{tabular}{|c|c|c|c|c|c|c|}
\hline \multirow[b]{2}{*}{ Arguments } & \multicolumn{2}{|c|}{ All voters } & \multicolumn{2}{|c|}{ Yes voters } & \multicolumn{2}{|c|}{ No voters } \\
\hline & YA & NA & YA & NA & YA & NA \\
\hline True & 0.54 & 0.76 & 0.56 & 0.78 & 0.53 & 0.73 \\
\hline Not true & 0.46 & 0.24 & 0.44 & 0.22 & 0.47 & 0.27 \\
\hline Justify & 0.23 & 0.22 & 0.26 & 0.32 & 0.22 & 0.18 \\
\hline Does not justify & 0.77 & 0.78 & 0.74 & 0.68 & 0.78 & 0.82 \\
\hline Influence & 0.27 & 0.36 & 0.31 & 0.39 & 0.26 & 0.34 \\
\hline Does not influence & 0.73 & 0.64 & 0.69 & 0.61 & 0.74 & 0.66 \\
\hline
\end{tabular}

Yes voters-people declaring an intention to vote Yes. No voters-people declaring an intention to vote No. The data in red represents a significant difference when the Yes and No arguments were compared. 


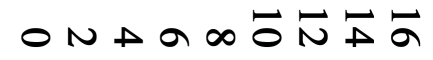
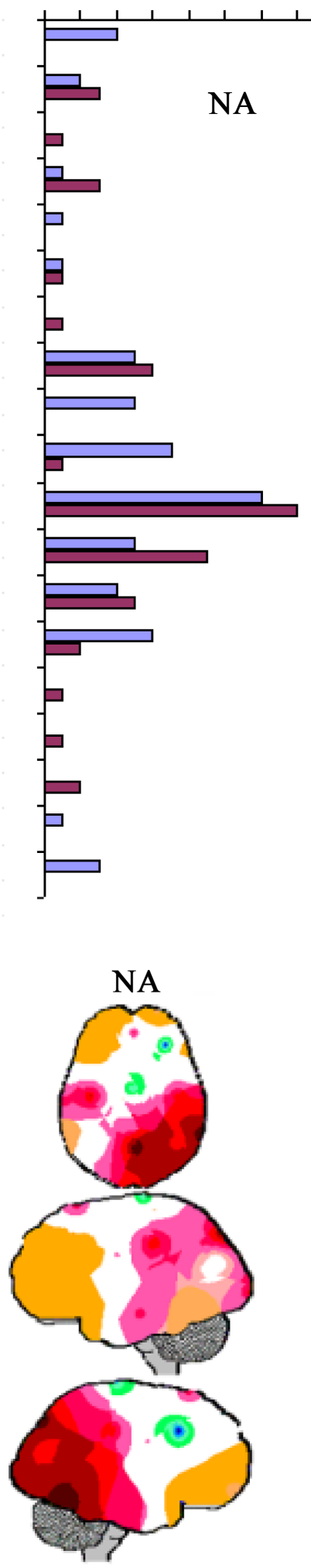

6-Superior Frontal Gyrus

7-Postcentral Gyrus

7-Precuneus

7-Superior Parietal Lobule

9-Middle Frontal Gyrus

9-Superior Frontal Gyrus

10-Middle Frontal Gyrus

10-Superior Frontal Gyrus

11-Middle Frontal Gyrus

11-Superior Frontal Gyrus

18-Cuneus

18-Middle Occipital Gyrus

19-Cuneus

19-Middle Occipital Gyrus

19-Fusiform Gyrus

22-Superior Temporal Gyrus

40-Inferior Parietal Lobule

40-Supramarginal Gyrus

47-Inferior Frontal Gyrus
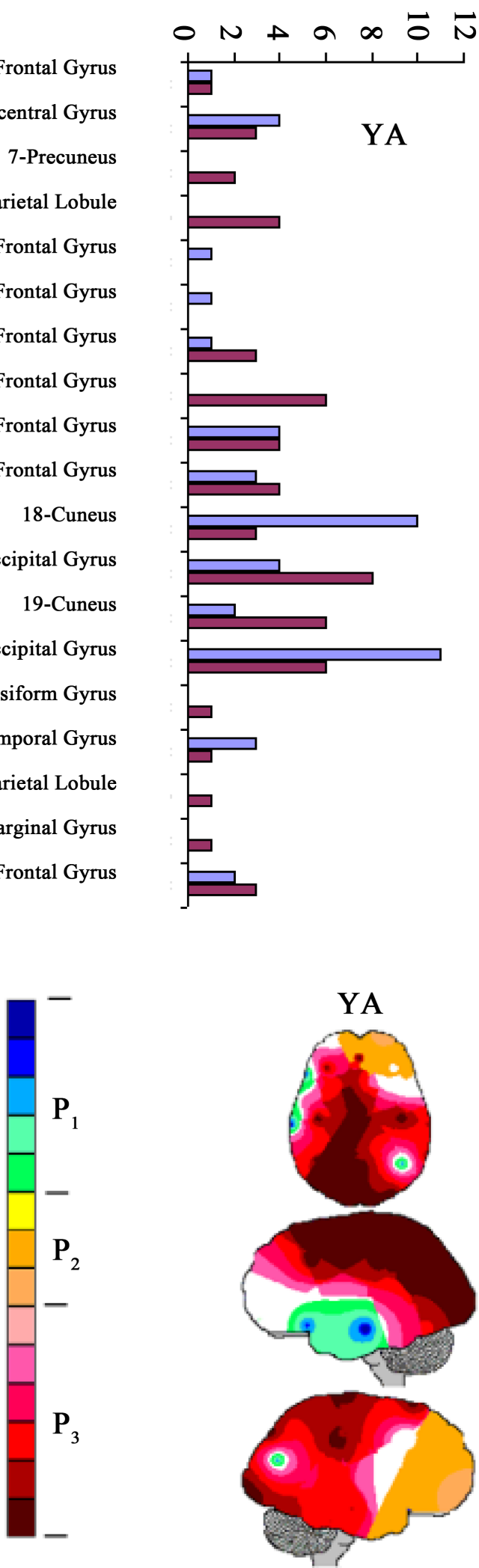

Figure 2. Truth evaluation: the most frequent locations of Loreta sources identified for NA and YA (upper graph) and PCA mappings associated with these identified sources. 

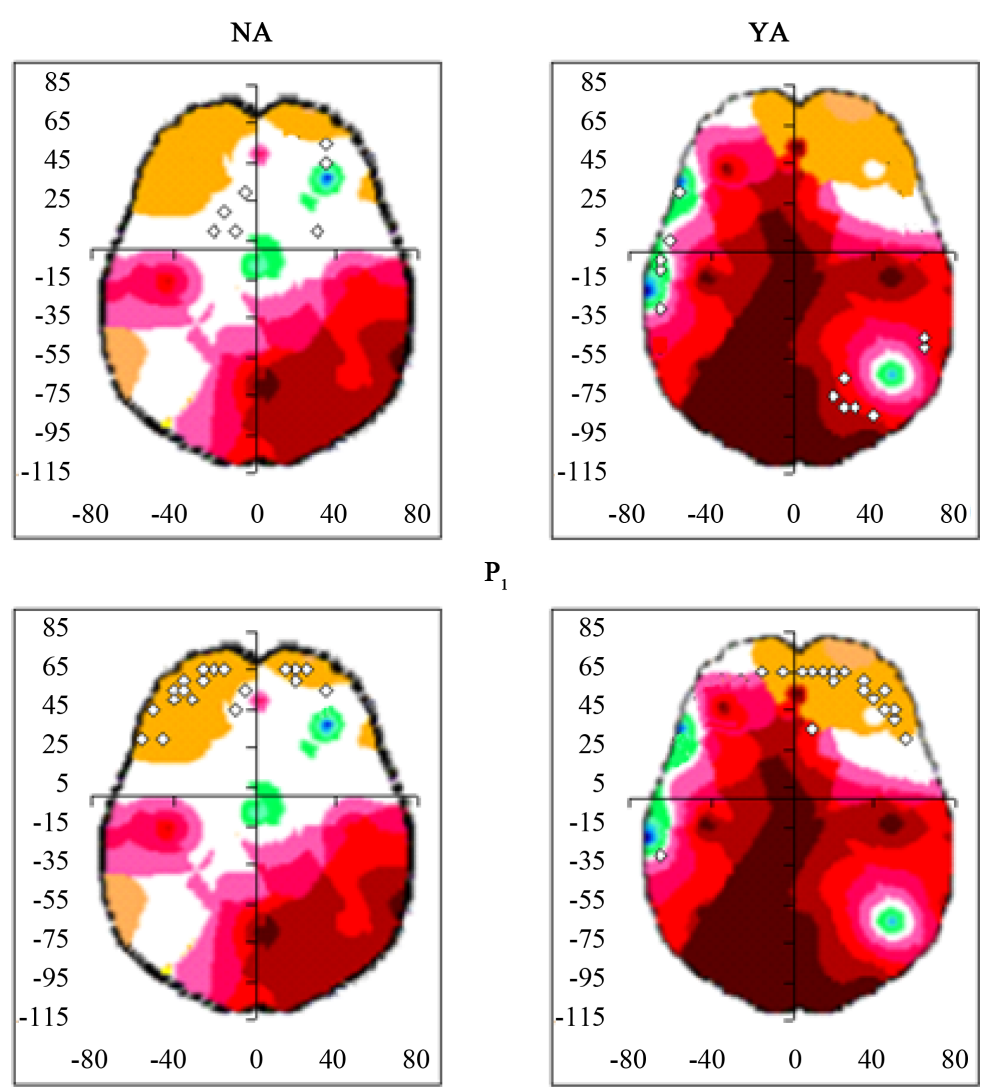

$\mathrm{P}_{1}$

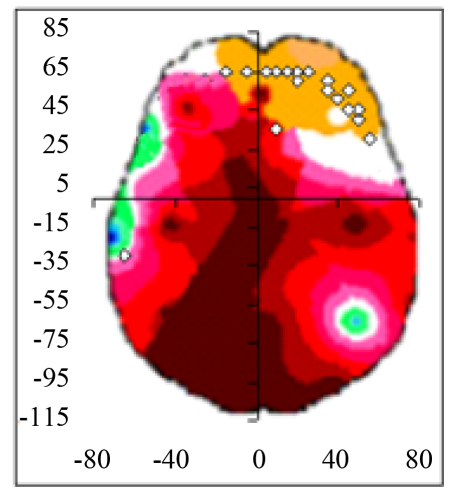

$\mathbf{P}_{2}$
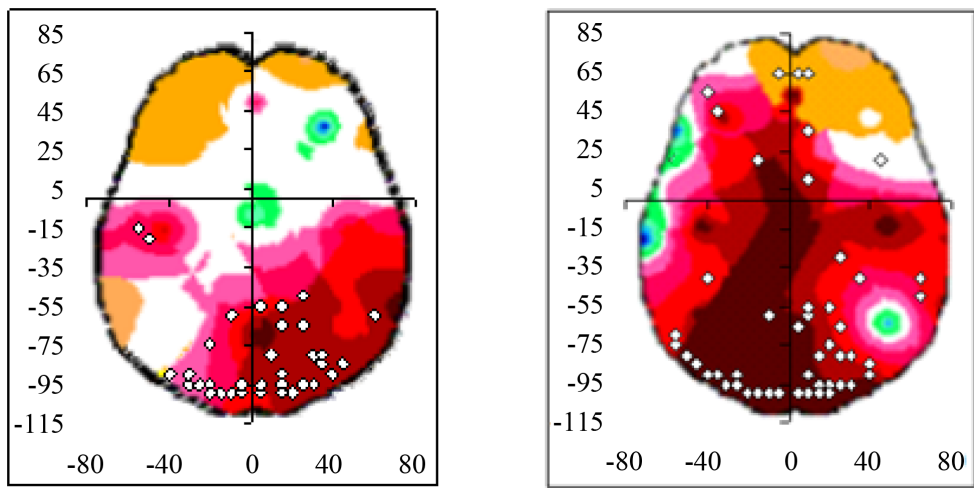

$\mathbf{P}_{3}$

Figure 3. PCA mappings and spatial location of those Loreta sources associated with each PCA pattern in case of truth evaluation. The sources are those described in Table 5.

Loreta analysis and PCA comparison shows that pattern $\mathrm{P}_{1}$ is correlated with $s_{l}$ located at BA 6, 9 and 10 in NA case and BA 7, 22, 40 and 47 in YA case. In addition, sources associated with $\mathrm{P}_{2}$ and located at Middle Frontal Gyrus (BA 9, 10 and 11), Superior Frontal Gyrus (BA 9, 10 and 11), Medial Frontal Gyrus (BA 10) and Inferior Frontal Gyrus (BA 47) are common to both NA and YA; whereas those located at Precuneus (BA 7); Superior Frontal Gyrus (BA 8), Supramarginal Gyrus (BA 40) and Middle Frontal Gyrus (BA 46) were specific to NA, and those located at Medial Frontal Gyrus (BA 9 and 11), Precentral Gyrus (BA 44) and Inferior Frontal Gyrus (BA 45) were specific to YA. In case of pattern $\mathrm{P}_{3}$, Postcentral Gyrus (BA 7), Superior Parietal Lobe (BA 7), Cuneus (BA 18 and 19) and Middle Occipital Gyrus (BA 18 and 19) were the only common source locations for NA and YA, all other sources are different for each type of argument. 


\section{A. F. Rocha et al.}

Table 5. Loreta sources associated with each PCA pattern: Truth Identification.

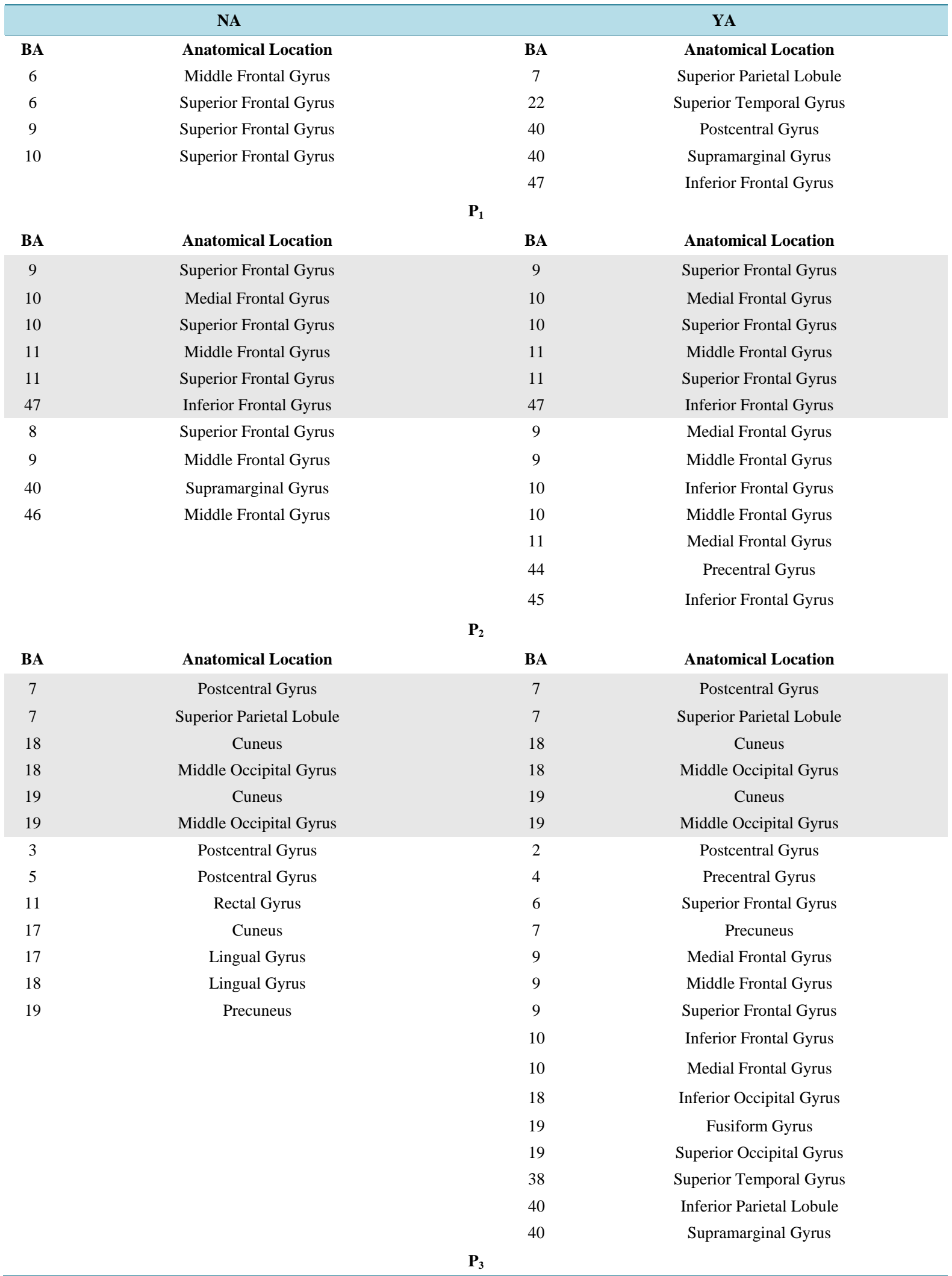

Grey background highlight common source locations. 


\subsubsection{Justification Evaluation}

Grand averages (Figure 2) were clearly different for YA and NA, having 50 significant moments in NA case and 80 of these moments in YA case. These differences resulted in two distinct LS sets of identified Loreta sources associated with Truth evaluation of each type of argument (Figure 2). Because of this PCA mappings associated with Truth evaluation were clearly different for YA and NA (Figure 4).

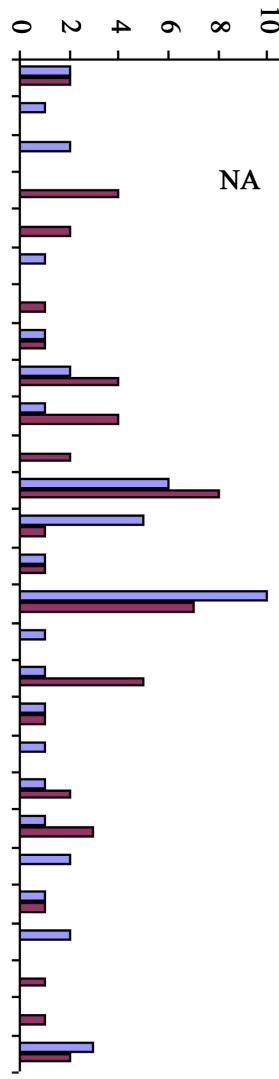

5-Postcentral Gyrus 6-Precentral Gyrus 6-Superior Frontal Gyrus -Superior Parietal Lobule 8-Middle Frontal Gyrus 8-Superior Frontal Gyrus 9-Superior Frontal Gyrus 10-Medial Frontal Gyrus 10-Middle Frontal Gyrus 10-Superior Frontal Gyrus 11-Medial Frontal Gyrus

11-Middle Frontal Gyrus 11-Superior Frontal Gyrus 17-Cuneus 18-Cuneus

18-Lingual Gyrus 18-Middle Occipital Gyrus 19-Precuneus 1-Inferior Temporal Gyrus 1-Middle Temporal Gyrus Superior Temporal Gyrus 37-Middle Occipital Gyrus Superior Temporal Gyrus 3-Middle Temporal Gyrus 40-Supramarginal Gyrus 46-Middle Frontal Gyrus 47-Inferior Frontal Gyrus
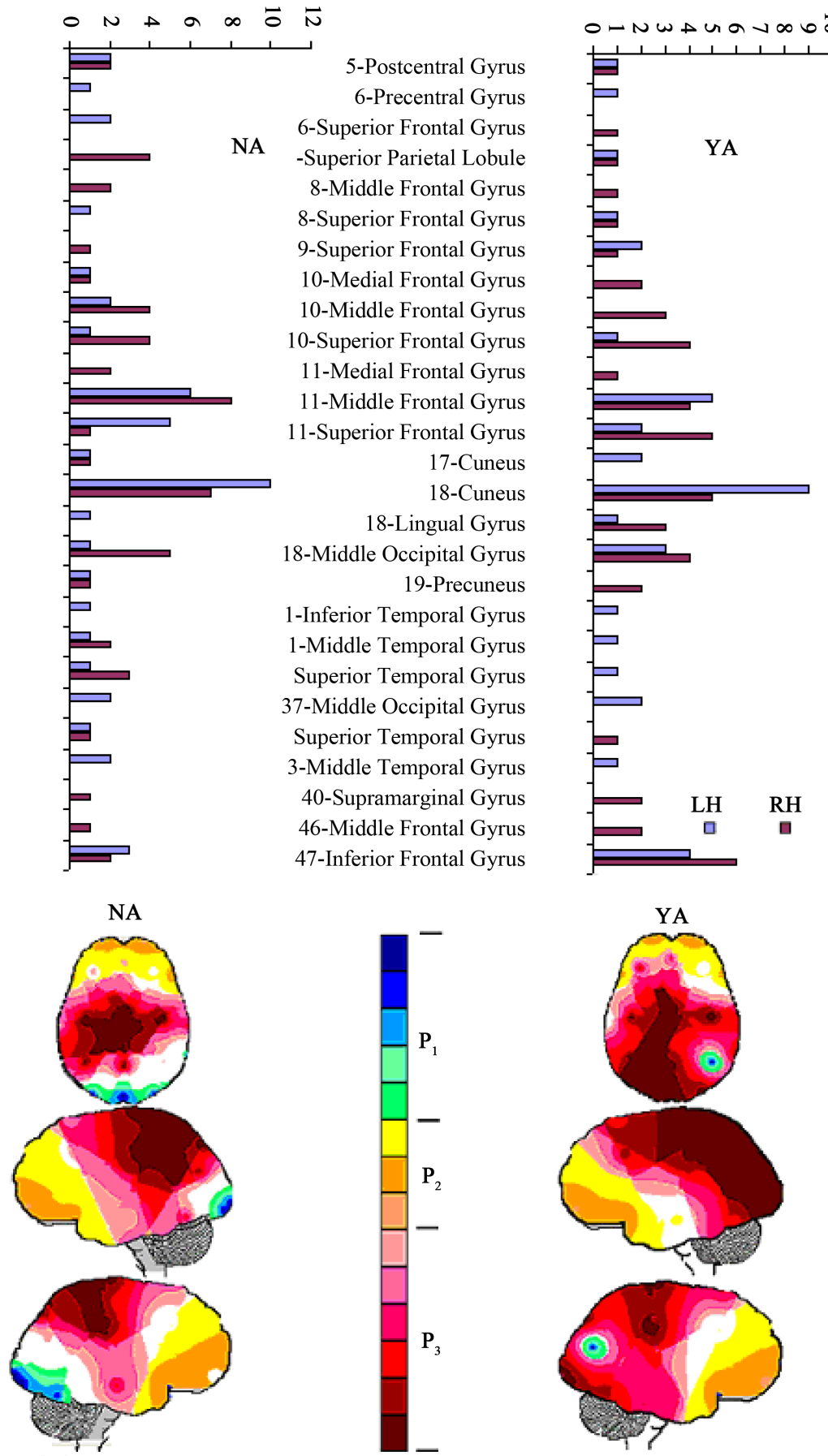

Figure 4. Justification evaluation: the most frequent locations of Loreta sources identified for NA and YA (upper graph) and PCA mappings (lower graph) associated with these identified sources. PCA mappings showing pattern $\mathrm{P}_{1}$ in green and to dark blue; pattern $\mathrm{P}_{2}$ in yellow and brown, and pattern $\mathrm{P}_{3}$ in rose to dark red. 
Loreta sources were mostly identified at BA 10, 11, 17, 18 and 47 for both types of argument but the frequency these sources were located at these locations differed for NA compared to YA.

PCA mappings associated with Justification evaluation were clearly different for YA and NA (Figure 4). The P1 pattern was reduced in electrode P4 for the YA case and in the occipital electrodes for the NA case. Pattern P2 was very similar for both YA and NA, consisting of bilateral frontal electrodes. Pattern 3 consisted of F3, C3, P3, O1, FZ, CZ, PZ, OZ, C4 and O2 responses in the YA case, and comprised the F3, C3, P3, CZ, PZ and C4 electrodes.

Loreta analysis and PCA comparison (Figure 5 and Table 6) shows that pattern $\mathrm{P}_{1}$ is correlated with $s_{l}$ lo-

NA
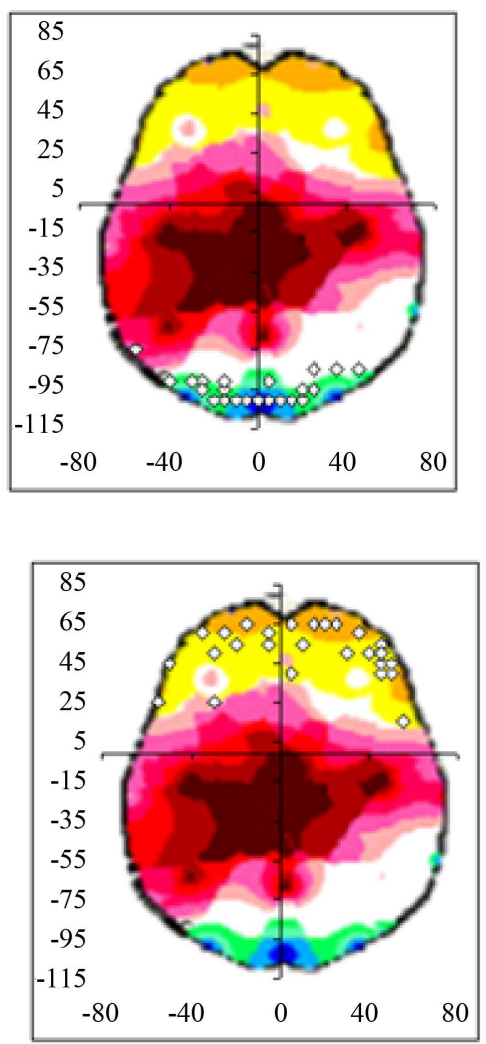

YA

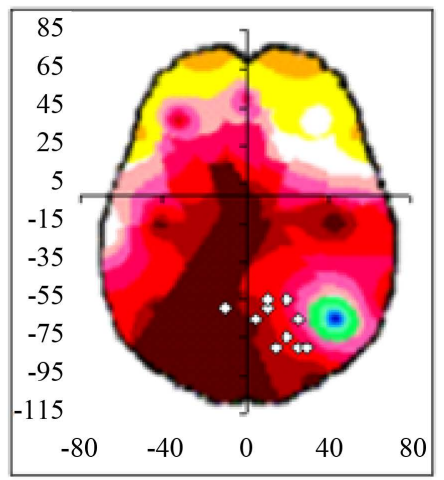

$P_{1}$

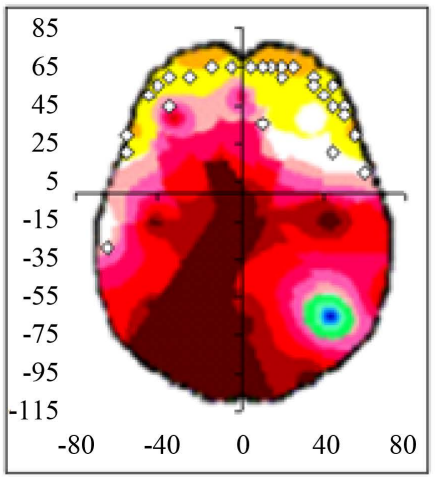

$P_{2}$

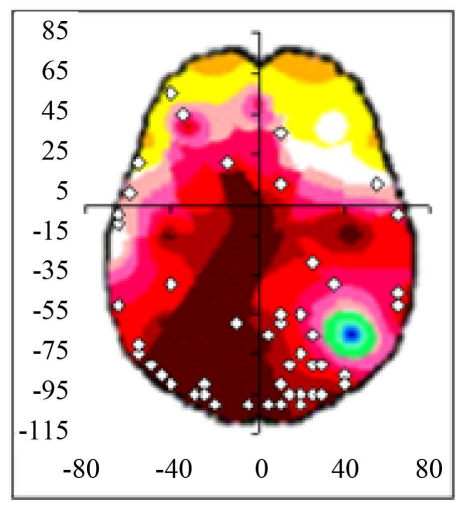

$\mathbf{P}_{3}$

Figure 5. PCA mappings and spatial location of those Loreta sources associated with each PCA pattern in case of Justification evaluation. The sources are those described in Table 6. 
Table 6. Loreta sources associated with each PCA pattern: Justification.

\begin{tabular}{|c|c|c|c|}
\hline \multicolumn{2}{|r|}{ NA } & \multicolumn{2}{|r|}{ YA } \\
\hline BA & Anatomical Location & BA & Anatomical Location \\
\hline 17 & Cuneus & 7 & Superior Parietal Lobule \\
\hline 18 & Cuneus & 22 & Superior Temporal Gyrus \\
\hline 18 & Inferior Occipital Gyrus & & \\
\hline 18 & Lingual Gyrus & & \\
\hline 18 & Middle Occipital Gyrus & & \\
\hline 19 & Cuneus & & \\
\hline 19 & Middle Occipital Gyrus & & \\
\hline 19 & Precuneus & & \\
\hline & & & \\
\hline BA & Anatomical Location & BA & Anatomical Location \\
\hline 8 & Superior Frontal Gyrus & 8 & Superior Frontal Gyrus \\
\hline 9 & Superior Frontal Gyrus & 9 & Superior Frontal Gyrus \\
\hline 10 & Medial Frontal Gyrus & 10 & Medial Frontal Gyrus \\
\hline 10 & Middle Frontal Gyrus & 10 & Middle Frontal Gyrus \\
\hline 10 & Superior Frontal Gyrus & 10 & Superior Frontal Gyrus \\
\hline 11 & Medial Frontal Gyrus & 11 & Medial Frontal Gyrus \\
\hline 11 & Middle Frontal Gyrus & 11 & Middle Frontal Gyrus \\
\hline 11 & Superior Frontal Gyrus & 11 & Superior Frontal Gyrus \\
\hline 40 & Supramarginal Gyrus & 40 & Supramarginal Gyrus \\
\hline 46 & Middle Frontal Gyrus & 46 & Middle Frontal Gyrus \\
\hline 47 & Inferior Frontal Gyrus & 47 & Inferior Frontal Gyrus \\
\hline 11 & Rectal Gyrus & 9 & Medial Frontal Gyrus \\
\hline \multirow[t]{4}{*}{40} & Inferior Parietal Lobule & 11 & Orbital Gyrus \\
\hline & & 44 & Precentral Gyrus \\
\hline & & 45 & Inferior Frontal Gyrus \\
\hline & & 47 & Orbital Gyrus \\
\hline \multicolumn{4}{|c|}{$\mathbf{P}_{2}$} \\
\hline BA & Anatomical Location & BA & Anatomical Location \\
\hline 6 & Superior Frontal Gyrus & 6 & Superior Frontal Gyrus \\
\hline 7 & Postcentral Gyrus & 7 & Postcentral Gyrus \\
\hline 7 & Superior Parietal Lobule & 7 & Superior Parietal Lobule \\
\hline 9 & Superior Frontal Gyrus & 9 & Superior Frontal Gyrus \\
\hline 19 & Precuneus & 19 & Cuneus \\
\hline 3 & Postcentral Gyrus & 2 & Postcentral Gyrus \\
\hline 5 & Postcentral Gyrus & 4 & Precentral Gyrus \\
\hline 6 & Medial Frontal Gyrus & 7 & Precuneus \\
\hline 6 & Middle Frontal Gyrus & 9 & Medial Frontal Gyrus \\
\hline 6 & Precentral Gyrus & 9 & Middle Frontal Gyrus \\
\hline 8 & Middle Frontal Gyrus & 10 & Inferior Frontal Gyrus \\
\hline 8 & Superior Frontal Gyrus & 10 & Medial Frontal Gyrus \\
\hline 20 & Inferior Temporal Gyrus & 18 & Cuneus \\
\hline 21 & Inferior Temporal Gyrus & 18 & Inferior Occipital Gyrus \\
\hline 21 & Middle Temporal Gyrus & 18 & Middle Occipital Gyrus \\
\hline \multirow[t]{6}{*}{22} & Superior Temporal Gyrus & 19 & Fusiform Gyrus \\
\hline & & 19 & Middle Occipital Gyrus \\
\hline & & 19 & Superior Occipital Gyrus \\
\hline & & 38 & Superior Temporal Gyrus \\
\hline & & 40 & Inferior Parietal Lobule \\
\hline & & 40 & Supramarginal Gyrus \\
\hline
\end{tabular}


cated at BA 17, 18 and 19 in NA case and BA 7 and 22 in YA case. In addition, sources associated with $\mathrm{P}_{2}$ and located at Middle Frontal Gyrus (BA 10, 11 and 46), Superior Frontal Gyrus (BA 8, 9, 10 and 11), Medial Frontal Gyrus (BA 10 and 11), Supramarginal Gyrus (BA 40) and Inferior Frontal Gyrus (BA 47) are common to both NA and YA; whereas those located at Rectal Gyrus (BA 11) and Inferior Parietal Gyrus (BA 40) were specific to NA, and those located at Orbital Gyrus (BA 11 and 47), Precentral Gyrus (BA 44) and Inferior Frontal Gyrus (BA 45) were specific to YA. In case of pattern $\mathrm{P}_{3}$, Postcentral Gyrus (BA 7) and Superior Frontal Gyrys (BA 6 and 9), were the only common source locations for NA and YA, all other sources are different for each type of argument.

\subsubsection{Influence Evaluation}

Grand averages (Figure 1) were clearly different for YA and NA, having 35 significant moments in NA case and 56 of these moments in YA case. These differences resulted in two distinct LS sets of identified Loreta sources associated with Truth evaluation of each type of argument (Figure 6). Because of this PCA mappings
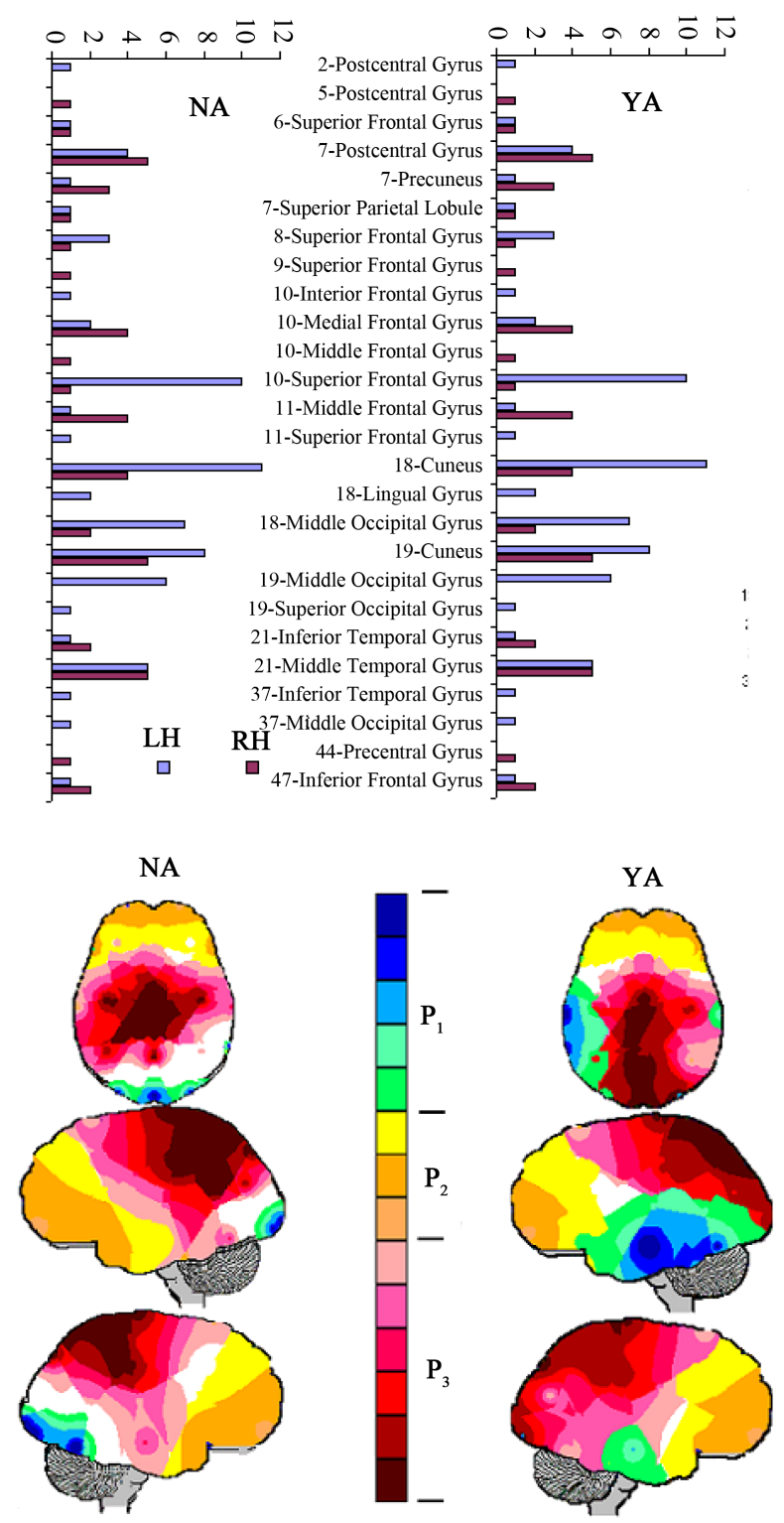

Figure 6. Influence evaluation: the most frequent locations of Loreta sources identified for NA and YA (upper graph) and PCA mappings (lower graph) associated with these identified sources. 
associated with Truth evaluation were clearly different for YA and NA (Figure 2).

Loreta sources were mostly identified at BA 7, 10, 11, 18 and 21 for both types of argument but the frequency these sources were located at these locations differed for NA compared to YA.

PCA mappings associated with Justification evaluation were clearly different for YA and NA (Figure 6). Pattern P1 consisted of F3, T5 and T6 in the YA case and occiptial electrodes in the NA case. Pattern P2 was very similar for both YA and NA, consisting of bilateral frontal electrodes. Pattern 3 consisted of P3, O1, FZ, CZ, PZ, OZ, C4, P4 and O2 in the YA case and the F3, C3, P3, CZ, PZ and C4 electrodes.

Loreta analysis and PCA comparison (Figure 7 and Table 7) shows that pattern $\mathrm{P}_{1}$ is correlated with $s_{l}$ mostly located at BA 18 in NA case and BA 21 and 22 in YA case. In addition, sources associated with $\mathrm{P}_{2}$ and located at Middle Frontal Gyrus (BA 10 and 11), Medial Frontal Gyrus (BA 10 and 11)) and Superior Frontal Gyrus (BA 8, 10 and 11) are common to both NA and YA; whereas those located at Middle Frontal Gyrus (BA 8 and 47) and Rectal Gyrus (BA 11, and those located at Inferior Frontal Gyrus (BA 10), Middle Frontal Gyrus (BA 46), Orbital Gyrus (BA 47), Precentral Gyrus (BA 44) and were specific to YA. In case of pattern $\mathrm{P}_{3}$, Postcentral Gyrus (BA 5 and 7), Superior Frontal Gyrys (BA 6), Inferior Temporal Gyrus (BA 21) and Superior Temporal Gyrus (BA 22) were the only common source locations for NA and YA, all other sources are different for each type of argument.

\section{Discussion}

A total of 1136 people living in the Great São Paulo area were asked whether media propaganda would influence or not their vote decision in the Brazilian Firearm Commerce Referendum. As discussed in the introduction, in order to justify a given type o vote, an argument has to be true and high probable. Each voter has their own set of arguments or reasons R for voting for (Yes) or against (No) firearm commerce control that may be dependent on many causes and believes. Therefore, it does not necessarily follow that a justified media argument will influence vote decision. In this line of reasoning, any media campaign is aimed to manipulate the inclusion of as many justified arguments pro a vote decision as possible in $\mathrm{R}$.

Poll opinion results showed that arguments (YA) for voting Yes was considered true by $50 \%$ of the volunteers and while $76 \%$ of them agreed with arguments (NA) for voting No, no matter their declared voting intention. Despite this, only $20 \%$ of the volunteers considered that media arguments would justify the intended vote. As discussed before, besides being true, an argument has to be high probable in order to justify the intended vote decision. Therefore, it may be said that media campaign failed in proving their arguments to probable enough to justify voting for or against firearm control. In line with these results, more than $60 \%$ of the volunteers declared that media propaganda would not influence their vote decision. Because for most of people, media arguments were not justified, media propaganda also failed in changing voter's set of reasons $R$. This was a remarkable finding because it shows that the vote decision was guided by reasons other than those that are usually discussed in a debate when any form of gun control gains national attention. The analysis of the EEGs recorded during the PQ responses shed some light on this subject.

Both Loreta analysis and PCA show that the same individual recruited different neural circuits during T, J and I epochs to analyze YA and NA irrespective of their vote intention about firearm commerce prohibition. YA analysis recruited larger set of neurons than those recruited by NA, indicating, perhaps that YA evaluation requires a reasoning more complex than that required by NA.

The core of YA arguments is an empirical fact that would characterize a social threat to be avoided by the firearm control. Voters would have to recall these facts from memory in order to evaluate their probability $p$ and associated damage. If $p>0$ then the argument is true and if $p>0$ then it is frequent. Now, if probability and damage are high an important social threat is identified. In contrast, the core of NA arguments implies reasoning about personal versus collective rights, causes of criminality, etc. In this case, it is necessary first to establish if the argument true and then its expected personal benefit and risk have to be estimated. Now, if argument is true, expected personal benefit is low and risk is high a strong case is made for No voting. Because of this, it is expected that neural circuits involved in YA and NA analysis have to be different as observed here. This is in line with other propositions in the literature, e.g., that of "exploration-explotation" dilemma by Nathaniel et al. [13].

It is proposed here that PCA pattern $\mathrm{P}_{3}$ it is associated with the memory recalling of the fact proposed by YA, because this pattern is associated with sources located at BA 9 and 10 in the frontal cortex [14]-[19], BA 18 and 19 in the posterior cortex [20] and BA 38 and 40 at the temporal cortex [14] [20] [21]. In addition, pattern $\mathrm{P}_{2}$ it 

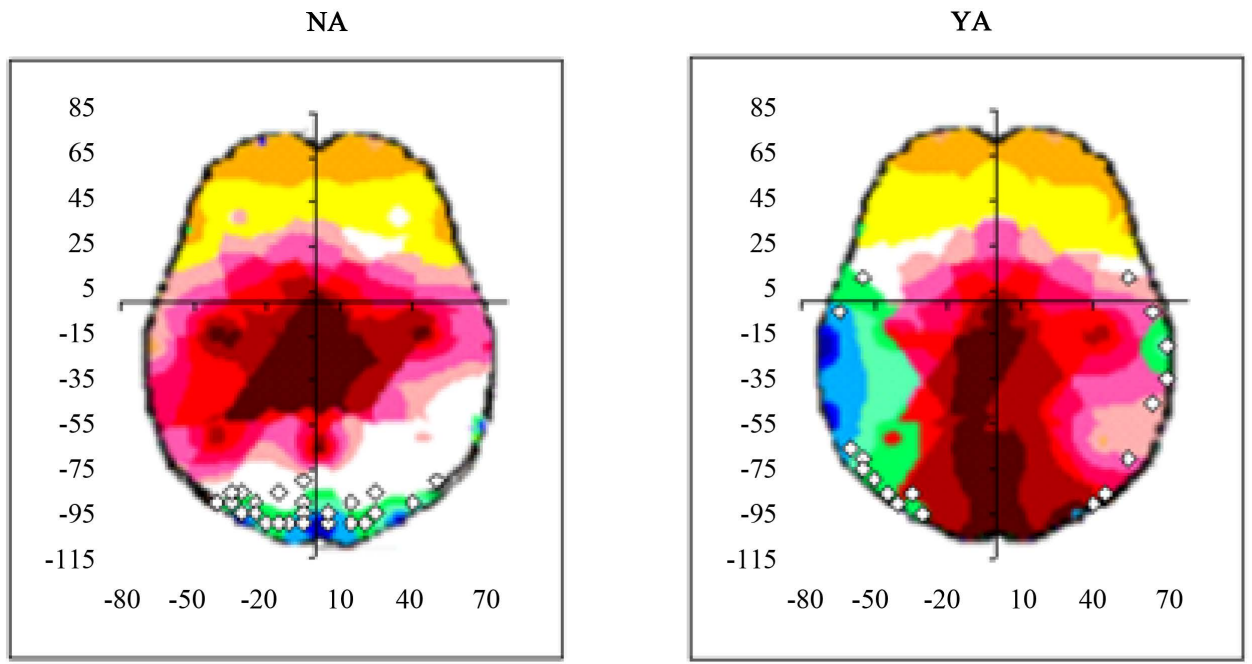

$\mathrm{F}_{1}$
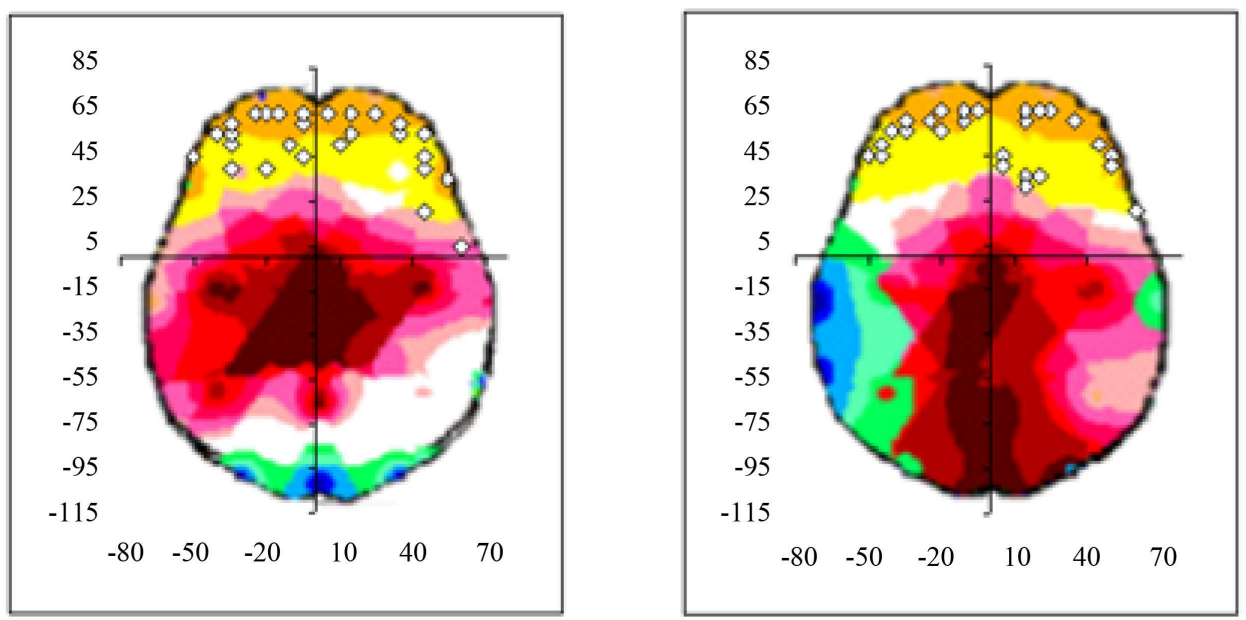

$\mathrm{F}_{2}$
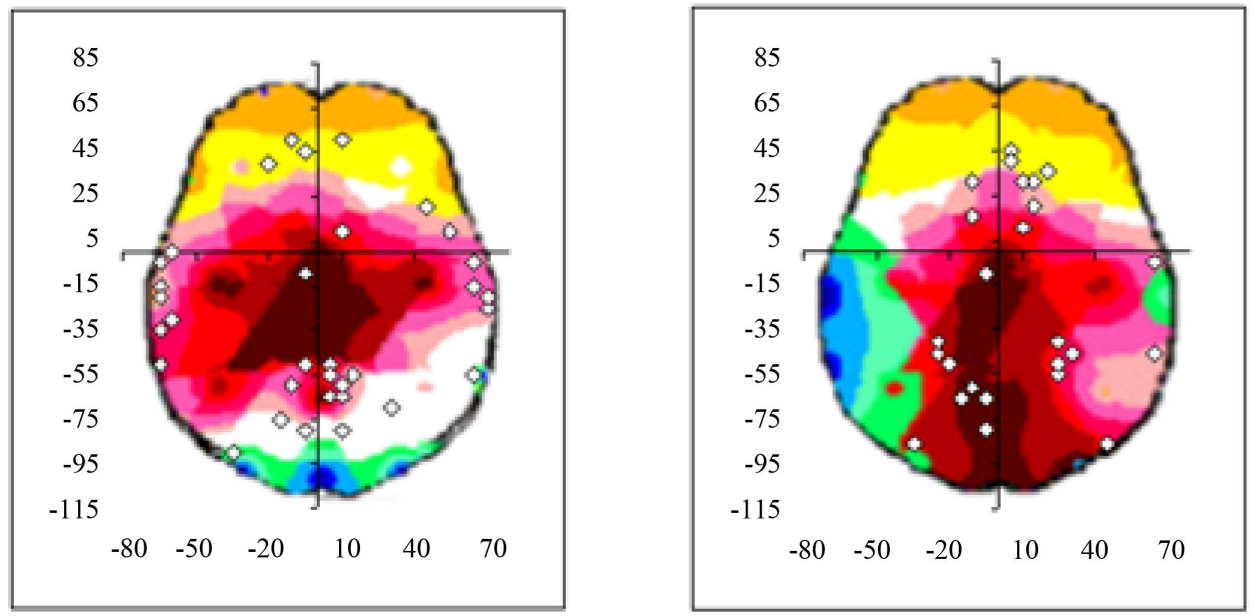

$\mathrm{F}_{3}$

Figure 7. PCA mappings and spatial location of those Loreta sources associated with each PCA pattern in case of Influence evaluation. The sources are those described in Table 7. 
Table 7. Loreta sources associated with each PCA pattern: Influence.

\begin{tabular}{|c|c|c|c|}
\hline \multicolumn{2}{|r|}{ NA } & \multicolumn{2}{|r|}{ YA } \\
\hline BA & Anatomical Location & BA & Anatomical Location \\
\hline 19 & Middle Temporal Gyrus & 19 & Middle Occipital Gyrus \\
\hline 18 & Cuneus & 19 & Inferior Occipital Gyrus \\
\hline 18 & Inferior Occipital Gyrus & 19 & Inferior Temporal Gyrus \\
\hline 18 & Lingual Gyrus & 19 & Superior Occipital Gyrus \\
\hline 18 & Middle Occipital Gyrus & 21 & Inferior Temporal Gyrus \\
\hline 19 & Cuneus & 21 & Middle Temporal Gyrus \\
\hline \multirow[t]{2}{*}{19} & Middle Occipital Gyrus & 22 & Superior Temporal Gyrus \\
\hline & & 19 & Middle Occipital Gyrus \\
\hline \multicolumn{4}{|c|}{$\mathbf{P}_{1}$} \\
\hline BA & Anatomical Location & BA & Anatomical Location \\
\hline 8 & Superior Frontal Gyrus & 8 & Superior Frontal Gyrus \\
\hline 9 & Superior Frontal Gyrus & 9 & Superior Frontal Gyrus \\
\hline 10 & Medial Frontal Gyrus & 10 & Medial Frontal Gyrus \\
\hline 10 & Middle Frontal Gyrus & 10 & Middle Frontal Gyrus \\
\hline 10 & Superior Frontal Gyrus & 10 & Superior Frontal Gyrus \\
\hline 11 & Medial Frontal Gyrus & 11 & Medial Frontal Gyrus \\
\hline 11 & Middle Frontal Gyrus & 11 & Middle Frontal Gyrus \\
\hline 11 & Superior Frontal Gyrus & 11 & Superior Frontal Gyrus \\
\hline 44 & Precentral Gyrus & 44 & Precentral Gyrus \\
\hline 47 & Inferior Frontal Gyrus & 47 & Inferior Frontal Gyrus \\
\hline 47 & Middle Frontal Gyrus & 47 & Orbital Gyrus \\
\hline 8 & Middle Frontal Gyrus & 10 & Inferior Frontal Gyrus \\
\hline 11 & Rectal Gyrus & 46 & Middle Frontal Gyrus \\
\hline \multicolumn{4}{|c|}{$\mathbf{P}_{2}$} \\
\hline BA & Anatomical Location & BA & Anatomical Location \\
\hline 5 & Postcentral Gyrus & 5 & 5-Postcentral Gyrus \\
\hline 6 & Superior Frontal Gyrus & 6 & 6-Superior Frontal Gyrus \\
\hline 7 & Postcentral Gyrus & 7 & 7-Postcentral Gyrus \\
\hline 7 & Superior Parietal Lobule & 7 & 7-Superior Parietal Lobule \\
\hline 8 & Superior Frontal Gyrus & 8 & 8-Superior Frontal Gyrus \\
\hline 21 & Inferior Temporal Gyrus & 21 & 21-Inferior Temporal Gyrus \\
\hline 22 & Superior Temporal Gyrus & 22 & 22-Superior Temporal Gyrus \\
\hline 3 & Postcentral Gyrus & 2 & 2-Postcentral Gyrus \\
\hline 6 & Medial Frontal Gyrus & 7 & 7-Precuneus \\
\hline 6 & Middle Frontal Gyrus & 19 & 19-Superior Occipital Gyrus \\
\hline 6 & Precentral Gyrus & & \\
\hline 8 & Middle Frontal Gyrus & & \\
\hline 19 & Precuneus & & \\
\hline 20 & Inferior Temporal Gyrus & & \\
\hline 21 & Middle Temporal Gyrus & & \\
\hline & & & \\
\hline
\end{tabular}


is associated mostly with sources located at the right frontal cortex (mostly BA 9, 10, 11 and 47) that has an important role in episodic memory handling as discussed by Henson et al. [22] and Lepage et al. [16].

Complementing the above hypothesis, it is assumed here that PCA pattern $\mathrm{P}_{3}$ it is associated with the analytical reasoning involved in establishing the veracity of the fact proposed by NA, because this pattern is associated with sources located at BA 11 in the frontal cortex, BA 3 and 5 in the parietal cortex and BA 17 and 18 in the posterior cortex [22]-[25]. In addition, pattern $\mathrm{P}_{2}$ it is associated mostly with sources located at the left frontal cortex (mostly BA 9, 10, 11, 46 and 47) that has in important role in analytical reasoning as proposed by Canessa et al. [22], Knauff et al. [23] and Mackey et al. [25].

Finally, it must be stressed that $\mathrm{P}_{1}$ is the largest and most distinctive PCA pattern associate with truth evaluation of YA and NA as it was the most distinctive pattern between Yes and No voters [6].

From the above, it is proposed here that pattern $\mathrm{P}_{2}$ disclosed those frontal executive neural circuits handling temporal-parietal-occipital circuits disclosed by pattern $\mathrm{P}_{3}$ and in charge of data recalling in case of episodic memory and YA analysis and in charge of logically inferring the truth of NA. Rocha et al. [6] also considered $\mathrm{P}_{2}$ as associated with executive frontal neural circuits handling those other neural circuits disclosed by $\mathrm{P}_{3}$ and in charge of differentiating Yes from No voters.

YA arguments were socially driven, which was typical for arguments in favor of any gun control in a variety of societies. ToM refers to the ability to attribute mental states to others and the ability to infer the emotional experiences of others (empathy), which are important processes in social cognition. Brain imaging studies in healthy subjects have described a brain system involving the medial prefrontal cortex, inferior frontal gyrus (IFG), superior temporal sulcus and temporal pole in ToM processing [7] [26]. In addition, the role of IFG in ToM circuits has been thought to block self-centered reasoning [8] [10] [27] [28]. YA sources were located at all these areas (Figure 2 and Figure 3) and while IFG located at BA 47 is common to both YA and NA analysis, IFG located at BA 45 is part of $\mathrm{P}_{2}$ in YA case but not in NA case. Taken together, these results corroborate the hypothesis that socially driven neural circuits are important for establishing the veracity of YA.

In contrast with the above findings, NA arguments were self-interest driven, which is typical of arguments against any gun control in a variety of societies. Humans know others as outside speakers, visual images and recognized actors stored in our retrospective memory. Our own selves are identified by inner speech, somesthetic imagery, actions and episodic/autobiographic memories. The superior frontal and lingual gyrus have been reported [24] [29]-[32] as important structures associated with self-intended actions. The precuneus is a structure considered as a hub connecting the parietal and prefrontal regions [33] [34], and thereby plays an important role in various functions, including retrospective, episodic and autobiographic memories [7] and self reasoning [7] [10] [27]. Many of the sources discriminating NA from YA are located in the superior frontal, fusiform and lingual regions as well as in the precuneus, supporting the hypothesis that self-related circuits are important in establishing NA truth. The precuneus is also among the structures where YA discriminating sources were located; however, these sources were located in Brodmann area 7 and 19 in the YA and NA cases, respectively. Furthermore, in the rectal gyrus, which is one of the regions where the NA discriminating sources were located, the authors proposed that it is involved in evaluating the degree of NA truth. These results corroborated the hypothesis that self-interest driven neural circuits are important for establishing the veracity of NA.

Patterns $\mathrm{P}_{2}$ and $\mathrm{P}_{3}$ dramatically changed from truth to justification evaluation in NA case. $\mathrm{P}_{2}$ and $\mathrm{P}_{3}$ are associated to sources located predominantly at the left hemisphere during truth evaluation and bilaterally located in case of justification analysis. In this case, $\mathrm{P}_{3}$ is also associated to sources located at more anterior places in comparison to truth evaluation. All patterns were similar during justification and influence evaluation for NA. As discussed above truth evaluation of NA implies logical inference whereas justification analysis implies to estimate expected benefits and risks. Because of this, neural circuits supporting each type of analysis to be different as observed here. In addition, NA were believed by more than $75 \%$ volunteers but $75 \%$ of then considered that they did not justify voting No. Therefore, it may be supposed that expected risks were considered greater than benefits. Because NAs were considered not justified they would not influence vote decision. Because risks were supposed greater than benefits NAs would not influence vote decision. This may explain because brain activity was similar during both $\mathrm{J}$ and I epochs.

Pattern $\mathrm{P}_{3}$ did not change from truth to justification evaluation in YA case but $\mathrm{P}_{2}$ was associated to sources located predominantly at the left hemisphere during truth evaluation and bilaterally located in case of justification analysis. In addition, pattern $\mathrm{P}_{2}$ did not change from justification to influence evaluation in YA case but $\mathrm{P}_{3}$ was associated with sources located at a small number of locations during influence than justification evaluation. 
To be considered as justified, YAs have to be true and frequent. Around $50 \%$ of the volunteers considered them as true, but less than $30 \%$ of them considered that arguments would justify vote. These means that most of volunteers did not considered the appointed fact as frequent or associated with an important social damage. But these evaluations are also of empirical nature. To be true the probability of the proposed fact has to be greater than 0 , and to be considered frequent it must be much greater than 0 . So, the same circuits must be involved in both analyses. Because YAs were considered not justified they would not influence vote decision as observed here. This may explain why because brain activity may involve a smaller number of areas during I epoch in comparison to J epoch.

\section{Conclusion}

In conclusion, it may be said that our results show that different neural circuits support YA and NA analyses because these analyses enrolled neurons located at different cortical areas. YA analysis was associated with activation of cortical areas known to be involved in retrospective and episodic memory as well as with areas known to be involved in evaluating others' intention. In contrast, NA analysis was associated with cortical areas that are proposed to be involved with self-interest evaluation. Moreover, information about neural mechanism involved in voting decision-making obtained in this work helped to differentiate distinct ontological origins of YA and NA.

\section{Acknowledgements}

This work was partially supported by LIM01-HCFMUSP, CNPQ and FAPESP.

\section{Ethical Aspects}

All participants signed an informed consent. This work has been approved by the Ethics Committee of the School of Medicine of the University of Sao Paulo.

\section{References}

[1] Rocha, A.F. (2013) Toward a Better Understanding of the Relationship between Neurosciences and Law. Law \& Neuroscience Journal, 4. http://papers.ssrn.com/abstract=2313182

[2] Hobbes, T. (1651) Leviathan. Penguin Classics, Penguin Books, New York.

[3] Rousseau, J.J. (1968) Du Contrat Social: Texte Original. Penguin Books Limited, London.

[4] Hart, H.L.A. (1961) Concept of Law. Oxford University Press, Oxford.

[5] Kelsen, H. (1960) Reine Rechteslehre. Verlag Fraz Deuticke, Viena.

[6] Rocha, A.F., Theoto, F., Burattini, M.N. and Massad, E. (2010) Neurodynamics of an Election. Brain Research, 1351, 198-211. http://dx.doi.org/10.1016/j.brainres.2010.06.046

[7] Frith, C.D. and Frith, U. (2006) The Neural Basis of Mentalizing. Neuron, 50, 531-534. http://dx.doi.org/10.1016/j.neuron.2006.05.001

[8] Cavanna, A.R. and Trimble, M.R. (2006) The Precuneus: A Review of Its Functional Anatomy and Behavioral Correlates. Brain, 129, 564-583. http://dx.doi.org/10.1093/brain/awl004

[9] Hartwright, C.E., Apperly, I.A. and Hansen, P.C. (2006) Multiple Roles for Executive Control in Belief-Desire Reasoning: Distinct Neural Networks Are Recruited for Self Perspective Inhibition and Complexity of Reasoning. NeuroImage, 61, 921-930. http://dx.doi.org/10.1016/j.neuroimage.2012.03.012

[10] Van den Ouden, H.E.M., Frith, U., Frith, C. and Blakemore, S.-J. (2005) Thinking about Intentions. NeuroImage, 28, 787-796. http://dx.doi.org/10.1016/j.neuroimage.2005.05.001

[11] Pasqual-Marqui, R.D., Esslen, M., Kochi, K. and Lehmann, D. (2002) Functional Imaging with Low-Resolution Brain Electromagnetic Tomography (LORETA): A Review. Methods and Findings in Experimental and Clinical Pharmacology, 24, 91-95.

[12] Rocha, F.T., Rocha, A.F., Massad, E. and Menezes, R.X. (2005) Brain Mappings of the Arithmetic Processing in Children and Adults. Cognitive Brain Research, 22, 359-372. http://dx.doi.org/10.1016/j.cogbrainres.2004.09.008

[13] Daw, N.D., O’Doherty, J.P., Dayan, P., Seymor, B. and Dolan, R.J. (2006) Cortical Substrates for Exploratory Decisions in Humans. Nature, 441, 876-879. http://dx.doi.org/10.1038/nature04766

[14] Addis, D.R. and Schacter, D.L. (2008) Constructive Episodic Simulation: Temporal Distance and Detail of Past and 
Future Events Modulate Hippocampal Engagement. Hippocampus, 18, 227-237. http://dx.doi.org/10.1002/hipo.20405

[15] Cabeza, R., Dolcos, F., Graham, R. and Nyberg, L. (2002) Similarities and Differences in the Neural Correlates of Episodic Memory Retrieval and Working Memory. Neuroimagen, 16, 317-330.

[16] Lepage, M., Ghaffar, O., Nyberg, L. and Tulving, E. (2000) Prefrontal Cortex and Episodic Memory Retrieval Mode Proceedings of the National Academy of Sciences of the United States of America, 97, 506-511. http://dx.doi.org/10.1073/pnas.97.1.506

[17] Platel, H., Baron, J.-C., Desgranges, B., Bernard, F. and Eustache, F. (2003) Semantic and Episodic Memory of Music Are Subserved by Distinct Neural Networks. NeuroImage, 20, 244-256. http://dx.doi.org/10.1016/S1053-8119(03)00287-8

[18] Ranganath, C., Johnson, M.K. and D’Ésposito, M. (2003) Prefrontal Activity Associated with Working Memory and Episodic Long-Term Memory. Neuropsychologia, 41, 378-389. http://dx.doi.org/10.1016/S0028-3932(02)00169-0

[19] Rugg, M.D., Fletcher, P.C., Frith, C.D., Frackowiak, R.S.J. and Dolan, R.J. (1996) Differential Activation of the Prefrontal Cortex in Successful and Unsuccessful Memory Retrieval. Brain, 119, 2073-2083. http://dx.doi.org/10.1093/brain/119.6.2073

[20] Baron, J.C. and Jones, T. (2012) Oxygen Metabolism, Oxygen Extraction and Positron Emission Tomography: Historical Perspective and Impact on Basic and Clinical Neuroscience. Neuroimage, 61, $492-504$. http://dx.doi.org/10.1016/j.neuroimage.2011.12.036

[21] Scheeringa, R., Petersson, K.M., Oostenveld, R., Norris, D.G., Hagoort, P. and Bastiaansen, M.C.M. (2009) Trial-by-Trial Coupling between EEG and BOLD Identifies Networks Related to Alpha and Theta EEG Power Increases during Working Memory Maintenance NeuroImage, 44, 1224-1238. http://dx.doi.org/10.1016/j.neuroimage.2008.08.041

[22] Canessa, N., Gorini, A., Cappa, S.F., Piattelli-Palmarini, M., Danna, M., Fazio, F. and Perani, D. (2005) The Effect of Social Content on Deductive Reasoning: An fMRI Study. Human Brain Mapping, 26, 30-43. http://dx.doi.org/10.1002/hbm.20114

[23] Henson, R.N.A., Shallice, T. and Dolan, R.J. (1999) Right Prefrontal Cortex and Episodic Memoryretrieval: A Functional MRI Test of the Monitoring Hypothesis. Brain, 122, 1367-1381. http://dx.doi.org/10.1093/brain/122.7.1367

[24] Knauff, K., Mulack, T., Kassubek, J., Salih, H.R. and Greenlee, M.W. (2002) Spatial Imagery in Deductive Reasoning: A Functional MRI Study. Cognitive Brain Research, 13, 203-212. http://dx.doi.org/10.1016/S0926-6410(01)00116-1

[25] Goel, V. and Dolan, R.J. (2001) Functional Neuroanatomy of Three-Term Relational Reasoning. Neuropsychologia, 39, 901-909. http://dx.doi.org/10.1016/S0028-3932(01)00024-0

[26] Mackey, A.P., Miller Singley, A.T. and Bunge, S.A. (2013) Intensive Reasoning Training Alters Patterns of Brain Connectivity at Rest. Journal of Neuroscience, 33, 4796-4803.

[27] Völlm, B.A., Taylor, A.N.W., Richardson, P., Corcoran, R., Stirling, J., McKie, S., et al. (2006) Neuronal Correlates of Theory of Mind and Empathy: A Functional Magnetic Resonance Imaging Study in a Nonverbal Task. NeuroImage, 29, 90-98. http://dx.doi.org/10.1016/j.neuroimage.2005.07.022

[28] Lundstrom, B.N., Ingvar, M. and Petersson, K.M. (2005) The Role of Percuneus and Frontal Cortex during Source Memory Episodic Retrieval. NeuroImage, 27, 824-834. http://dx.doi.org/10.1016/j.neuroimage.2005.05.008

[29] Van der Meer, L., Groenewold, N.A., Nolen, W.A., Pijnenborg, M. and Aleman, A. (2011) Inhibit Yourself and Understand the Other: Neural Basis of Distinct Processes Underlying Theory of Mind. NeuroImage, 56, 2364-2374. http://dx.doi.org/10.1016/j.neuroimage.2011.03.053

[30] Martino, J., Gabarrós, A., Deus, J., Juncadella, M., Acebes, J.J., Torres, A. and Pujol, J. (2011) Intrasurgical Mapping of Complex Motor Function in the Superior Frontal Gyrus. Neuroscience, 179, 131-142. http://dx.doi.org/10.1016/j.neuroscience.2011.01.047

[31] Nakagawa, S., Nishiike, S., Tonoike, M., Takeda, N. and Kubo, T. (2002) Measurements of Brain Magnetic Fields Associated with Apparent Self-Motion. International Congress Series, 1232, 367-371. http://dx.doi.org/10.1016/S0531-5131(01)00790-7

[32] Samson, D., Apperly, I.A., Chiavarino, C. and Humphreys, G.W. (2004) Left Tempoparietal Junction Is Necessary for Representing Someone Else's Belief. Nature Neuroscience, 7, 499-500. http://dx.doi.org/10.1038/nn1223

[33] Sulpizio, V., Committeri, G., Lambrey, S., Berthoz, A. and Galati, G. (2013) Selective Role of Lingual/Parahippocampal Gyrus and Retrosplenial Complex in Spatial Memory across Viewpoint Changes Relative to the Environmental Reference Frame. Behavioral Brain Research, 242, 62-75. http://dx.doi.org/10.1016/j.bbr.2012.12.031

[34] Bullmore, E. and Sporns, O. (2009) Complex Brain Networks: Graph Theoretical Analysis of Structural and Functional Systems. Nature Reviews Neuroscience, 10, 186-198. http://dx.doi.org/10.1038/nrn2575 
Scientific Research Publishing (SCIRP) is one of the largest Open Access journal publishers. It is currently publishing more than 200 open access, online, peer-reviewed journals covering a wide range of academic disciplines. SCIRP serves the worldwide academic communities and contributes to the progress and application of science with its publication.

Other selected journals from SCIRP are listed as below. Submit your manuscript to us via either submit@scirp.org or Online Submission Portal.
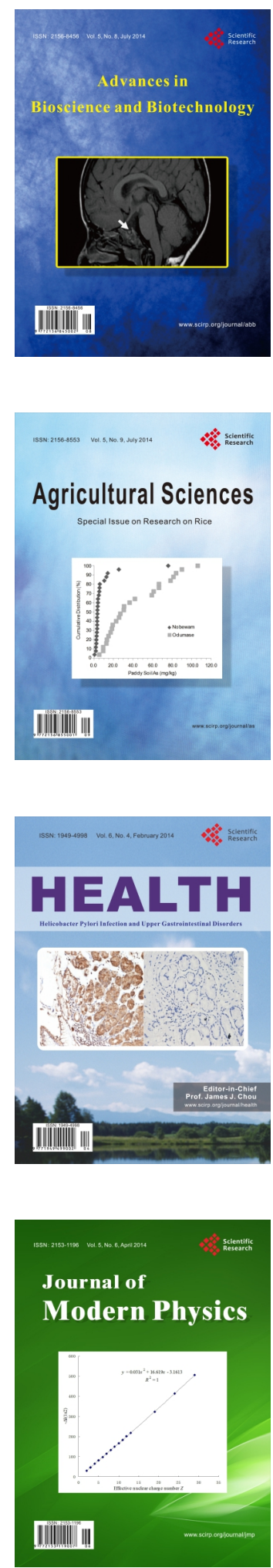
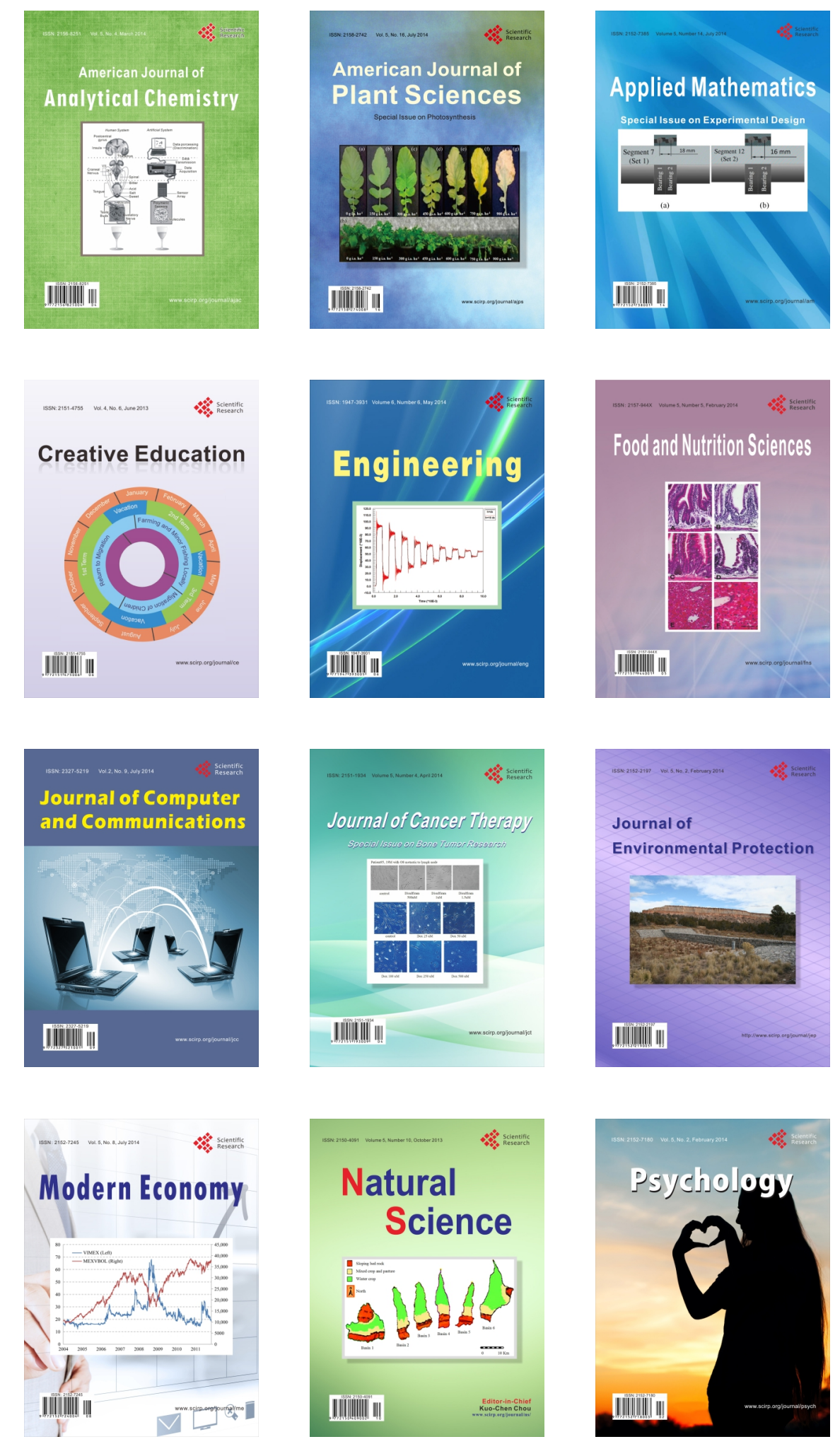